\title{
Diet and the role of altered carbohydrate absorption in the treatment of noninsulin- dependent diabetes mellitus
}

\author{
THOMAS MS WOLEVER MD PhD
}

\begin{abstract}
TMS WOLEVER. Diet and the role of altered carbohydrate absorption in the treatment of noninsulin-dependent diabetes mellitus. Can J Gastroenterol 1996;10(1):29-36. The gastrointestinal tract has no clear role in the pathophysiology of noninsulindependent diabetes mellitus (NIDDM), but it may be an appropriate site for therapeutic intervention, specifically changes in diet, meal frequency and medications. Studies suggest that for patients with NIDDM, a calorie-restricted, high carbohydrate diet low in fat and rich in fibre may improve glycemic control, mitigate the risk of atherosclerosis and retard such diabetic complications as nephropathy and retinopathy. Increased meal frequency slows the rate of carbohydrate absorption, flattens blood insulin responses and reduces serum cholesterol. New therapeutic interventions, such as soluble fibre, low glycemic index foods or alpha glucosidase inhibitors, can further slow carbohydrate absorption and thus reduce secondary risks from hyperglycemia and hyperinsulinemia.
\end{abstract}

Key Words: Alpha glucoside inhibitors, Diabetes mellitus, Hyperglycemia, Hyperinsulinemia
Régime alimentaire et rôle d'une mauvaise absorption des glucides dans le traitement du diabète sucré non insulino-dépendant

RÉSUMÉ : Le tractus gastro-intestinal ne joue pas de rôle défini dans la physiopathologie du diabète sucré non insulino-dépendant (DSNID), mais il peut constituer un domaine d'intervention thérapeutique approprié, spécialement en ce qui concerne l'alimentation, la fréquence des repas et la prise des médicaments. Selon certaines études menées chez des patients atteints de DSNID, un régime alimentaire pauvre en calories et riche en glucides, faible en gras et riche en fibres peut améliorer la maitrise de la glycémie, réduire les risques d'athérosclérose et retarder les complications du diabète, dont la néphropathie et la rétinopathie. La prise de repas plus fréquents ralentit le taux d'absorption des glucides, régularise les réponses insuliniques sanguines et abaissent le cholestérol sérique. De nouvelles interventions thérapeutiques comme la prise de fibres solubles, d'aliments à faible indice glycémique ou inhibiteurs de l'alpha-glucosidase, peuvent ralentir davantage l'absorption des glucides et ainsi réduire les risques d'hyperglycémie et d'hyperinsulinémie.
$\mathrm{T}$ he goals of noninsulin-dependent diabetes mellitus (NIDDM) treatment are to reduce the incidence of symptomatic glycemic abnormalities, delay or lessen microvascular complications and reduce risk factors for macrovascular complications (eg, atherosclerotic vascular disease). The gastrointestinal tract has no clear role in the pathogenesis of NIDDM; however, it may be an effective site for therapeutic intervention. Glucose metabolism and certain dyslipidemias can be effectively manipulated through changes in dietary content, meal frequency or use of innova- tive medications. As an adjunct to standard medical management (eg, diet, exercise, sulphonylureas, biguanides, insulin administration) interventions that modulate gastrointestinal function can be used to help persons with NIDDM realize their treatment goals.

\section{PATHOPHYSIOLOGY OF NIDDM}

Individuals with NIDDM have impaired nutrient metabolism primarily because of insulin resistance in key target tissues (eg, liver, muscle, adipose tissue) (1). Insulin resis-

Department of Nutritional Sciences, Faculty of Medicine, University of Toronto, and Clinical Nutrition and Risk Factor Modification Center, St Michael's Hospital, Toronto, Ontario

Correspondence: Dr TMS Wolever, Associate Professor, Department of Nutritional Sciences, University of Toronto, 150 College Street, Toronto, Ontario M5S 1A8. Telephone 416-978-5556, fax 416-978-5882

Received for publication January 18, 1995. Accepted May 4, 1995 
TABLE 1

Toxic effects of hyperglycemia on pancreatic function

\begin{tabular}{lcccc}
\hline \multicolumn{4}{c}{ Fasting blood glucose (mmol/L) } \\
Insulin secretion & $\mathbf{6 - 7}$ & $\mathbf{8 - 9}$ & $\mathbf{1 0 - 1 1}$ & $>11$ \\
\hline 1. Fasting & Normal to & Normal to & Normal to & $\downarrow$ \\
increased & increased & increased & \\
$\begin{array}{l}\text { 2. Postprandial } \\
\begin{array}{c}\text { a. Early phase } \\
\text { (release of } \\
\text { stored insulin) }\end{array}\end{array}$ & $\downarrow$ & $\downarrow$ & $\downarrow$ & $\downarrow$ \\
$\begin{array}{c}\text { b. Late phase } \\
\text { (release of } \\
\text { newly synthe- } \\
\text { sized insulin) }\end{array}$ & Normal to & Normal* & Normal to & $\downarrow$ \\
increased & & & decreased & \\
${ }^{*}$ Normal serum insulin, but insufficient to maintain euglycemia in response to
\end{tabular}

this glucose load

TABLE 2

Results of the Diabetes Control and Complications Trial

\begin{tabular}{|c|c|c|c|}
\hline Complications & $\begin{array}{l}\text { ic control as se } \\
\text { Conventional } \\
\text { therapy }\end{array}$ & $\begin{array}{c}\text { condary interventi } \\
\text { Intensive therapy } \\
\text { (rate/100 patient- } \\
\text { years) }\end{array}$ & $\begin{array}{l}\text { n in IDDM } \\
\text { Risk } \\
\text { reduction } \\
(\%)\end{array}$ \\
\hline \multicolumn{4}{|l|}{ Retinopathy } \\
\hline Mild & 7.8 & 3.7 & 54 \\
\hline Severe & 2.4 & 1.1 & 47 \\
\hline \multicolumn{4}{|l|}{ Nephropathy } \\
\hline Mild & 5.7 & 3.6 & 43 \\
\hline Severe & 1.4 & 0.6 & 54 \\
\hline Neuropathy* & 16.1 & 7.0 & 57 \\
\hline $\begin{array}{l}\text { Mean glucose } \\
(\mathrm{mmol} / \mathrm{L})\end{array}$ & 12.8 & 8.6 & \\
\hline $\begin{array}{l}\text { Mean glycosylated } \\
\text { hemoglobin (\%) }\end{array}$ & $9 \%$ & $7 \%$ & \\
\hline
\end{tabular}

Data from reference 6. *Assessed after five years and excludes patients with clinical neuropathy at onset of trial. IDDM Insulin-dependent diabetes mellitus

tance may be partly genetic, but is also augmented by obesity and the toxic effects of postprandial or persisting $24 \mathrm{~h}$ hyperglycemia (2). As insulin resistance develops, the pancreas reacts to persisting hyperglycemia by increasing secondphase insulin secretion. Initially, pancreatic compensation is able to maintain near-normal glucose metabolism at the expense of hyperinsulinemia (3). As insulin resistance increases, however, there is progressive decline in systemic glucose tolerance. Eventually, pancreatic capacity to synthesize and release sufficient insulin to overcome systemic insulin resistance is exceeded and metabolic decompensation begins (4).

Insulin resistance causes metabolic dysfunction in both the liver and muscle. In the liver gluconeogenesis is not inhibited appropriately and nocturnal/early morning hyperglycemia results. In peripheral muscles glucose use is impaired, resulting in enhanced oxidation of free fatty acids and other metabolic dysfunction $(2,5)$.

For years before the diagnosis of NIDDM is made, chronic mild elevation of blood glucose may contribute to the development of insulin resistance in the periphery. Chronic hyperglycemia is also believed to affect beta cells' ability to secrete insulin (Table 1).
TABLE 3

Results of the Stockholm Diabetes Intervention Study: Glycemic control as secondary intervention in insulindependent diabetes mellitus

\begin{tabular}{lcc}
\hline Complications & $\begin{array}{c}\text { Conventional } \\
\text { therapy }\end{array}$ & $\begin{array}{c}\text { Intensive } \\
\text { therapy }\end{array}$ \\
\hline $\begin{array}{l}\text { Patients with development of } \\
\text { serious retinopathy }(\%)\end{array}$ & 52 & 27 \\
$\begin{array}{c}\text { Nephropathy - patients developing } \\
\text { albuminuria }>200 \mu \mathrm{g} / \mathrm{min}\end{array}$ & 9 patients & 1 patient \\
$\begin{array}{l}\text { Neuropathy - patients reporting } \\
\text { symptoms at } 7.5 \text { years }(\%)\end{array}$ & 11 & 2 \\
$\begin{array}{l}\text { Mean glycosylated hemoglobin }(\%) \\
\text { Dean }\end{array}$ & 8.6 & 7 \\
\hline
\end{tabular}

Data from reference 7

\section{CLINICAL IMPLICATIONS OF HYPERGLYCEMIA}

For many years clinicians have suspected a relationship between glycemic control and the development of diabetic microvascular complications (eg, retinopathy, neuropathy, nephropathy). Only recently, however, have convincing data become available to support the therapeutic value of good control of blood sugar levels in clinical practice.

The Diabetes Control and Complications Trial (6) and the Stockholm Diabetes Intervention Study (7) are two long term, multicentre studies that independently demonstrated that better than usual ('tight') glycemic control delayed the onset and slowed the progression of microvascular complications in persons with insulin-dependent diabetes mellitus (IDDM) (Tables 2,3). Intensive therapy reduced the development of hypocholesterolemia, defined as a serum concentration of low density lipoprotein (LDL) cholesterol greater than $4.14 \mathrm{mmol} / \mathrm{L}$, by $34 \%$. Cardiovascular events were reduced by intensive therapy but this change was not statistically significant $(0.5$ events versus 0.8 events $/ 100$ patientyears). The relative youth of the patients made the detection of treatment-related differences in rates of macrovascular events unlikely.

Although individuals with NIDDM did not participate in these trials, it is believed that the results may apply to them because the mechanisms by which glucose causes complications are presumed to be the same in both types of diabetes $(8,9)$. Glycemic control may be only one of several factors that contribute substantially to the onset or progression of microvascular complications in NIDDM $(10,11)$. Further research is underway to determine the relationship between glycemic control and complications for people with NIDDM $(12-14)$.

\section{CLINICAL IMPLICATIONS OF HYPERINSULINEMIA}

There are good data to suggest that hyperinsulinemia promotes the development of accelerated atherosclerosis in NIDDM $(1,15)$. In one animal study on the effects of hyperinsulinemia, insulin administration stimulated proliferation of atheromas within blood vessels and increased cholesterol synthesis. Studies in humans confirm that insulin also plays a critical and permissive role in the endogenous synthesis of cholesterol (16), an important risk factor in atherogenesis 
(17). Insulin resistance may also contribute to the hypertension that is observed in NIDDM and other insulin-resistant states by enhancing renal sodium reabsorption or by directly stimulating the sympathetic nervous system (18).

Although the relationship among human hyperinsulinemia, insulin resistance and clinical diseases is not yet completely understood, these studies illustrate some of the ways in which hyperinsulinemia may contribute to accelerated atherosclerosis in patients with NIDDM (15-18).

\section{ROLE OF DIET IN THE CLINICAL EXPRESSION OF NIDDM}

Diet/gene interaction: In animals with experimentally induced beta cell dysfunction, a high fat intake caused marked fasting hyperglycemia and exaggerated glycemic responses to stress. When animals with equivalent beta cell defects were fed high starch diets, they maintained normal insulin sensitivity and fasting blood sugar, and displayed only mild impairment of glucose tolerance (19).

Human studies also suggest that dietary intake affects the clinical expression of NIDDM. Among Pima Indians, known to be genetically predisposed to NIDDM, diet can be a critical factor in whether diabetes is expressed (20). One study showed declines in glucose tolerance, glucose disposal and beta cell sensitivity to insulin after subjects were switched from the traditional Pima diet (70\% of calories from carbohydrates, $15 \%$ from fat) to a high fat modern diet ( $30 \%$ from carbohydrates, $50 \%$ from fat). Similar diabetogenic effects of the latter high fat diet were also found in Caucasians entered in that study (20).

Diet and development of complications: Diet may also play a role in the development and progression of diabetic complications although the results are not entirely consistent and more work is needed in the area. In one retrospective study (21), diabetics who developed retinopathy were found to have lower daily intakes of carbohydrate and fibre, and more calories from protein than diabetics who did not develop retinopathy.

Another study showed that lipid lowering by a low fat diet and/or hypolipidemic drugs improved hard retinal exudates, decreased microaneurysms and improved overall vision in patients with NIDDM with established diabetic retinopathy (22). It has also been reported that there is an increased incidence of certain types of cataracts among diabetic individuals who have diet-related vitamin and mineral deficiencies (23).

\section{CURRENT NUTRITIONAL RECOMMENDATIONS AND CONTROVERSIES}

Weight loss and glycemic control: The nutritional intervention recommended most frequently for patients with NIDDM is weight loss. Obesity complicates and worsens glycemic control for persons with NIDDM by increasing insulin resistance in both the liver and peripheral tissues (2).

There are many approaches to weight loss including low calorie diets, low fat diets combined with exercise and protein-sparing modified fasts. Although long term compli- ance with weight loss plans is difficult for many obese persons with NIDDM, current recommendations favour an energy controlled, high fibre diet in combination with exercise and/or behaviour modification counselling (24). For sustained weight reduction, a weight loss of no more than 1 $\mathrm{kg} / \mathrm{week}$ is recommended. Theoretically this can be achieved with a reduction in energy intake of $500 \mathrm{Kcal} /$ day, but the level of energy intake recommended needs to be individualized and depends on many factors, such as the level of physical activity undertaken by the individual. Glycemic improvement due to weight reduction may be predicted after a weight loss of only 2.3 to $4.5 \mathrm{~kg}$.

Despite the theoretical value of weight loss for obese persons with NIDDM, some who lose weight do not show improvement in blood glucose control (25). The effectiveness of weight loss as a clinical intervention may depend on the duration of diabetes, and the individual's insulin reserve and maintenance of the lower body weight (26). Recent studies suggest that the improvement in blood glucose control is more a function of reduced nutrient load rather than reduced adipose tissue mass per se (27). Thus, after a period of weight loss on a hypocaloric diet, when a weight-maintaining diet is reestablished, blood glucose levels begin to rise again (28). Patients whose blood sugar control does not improve after a trial of weight loss may require exercise, oral hypoglycemics or other pharmacological interventions to achieve glycemic control (25).

Canadian Diabetes Association dietary recommendations: The Canadian Diabetes Association recommends a calorierestricted, low fat, high carbohydrate, protein-limited, fibre-rich diet for all individuals with NIDDM (29). According to these recommendations, less than $30 \%$ of total calories should come from fat, 55 to $60 \%$ from carbohydrates and 12 to $20 \%$ from protein, with up to $40 \mathrm{~g} /$ day of fibre. The reduction of fat should be achieved primarily by a reduction of saturated fatty acids to less than $10 \%$ of energy. Polyunsaturated fat should contribute no more than 10\% of energy with the remainder supplied by monounsaturated fat.

Dietary carbohydrate: There is some controversy regarding the purported benefits of the high carbohydrate intake recommended for persons with NIDDM. Some data suggest that an increased carbohydrate intake may increase blood glucose and insulin, temporarily increase triglyceride concentrations and reduce beneficial high density lipoprotein (HDL) cholesterol (30). However, these changes may be transient and are not universal findings $(31,32)$.

Some research suggests that, in subjects with NIDDM, replacing saturated fat with monounsaturated fat may benefit lipid metabolism more than increasing the percentage of carbohydrate consumed (33). However, other studies were unable to demonstrate significant glycemic or lipid improvements due to increasing monounsaturated fat intake compared with high carbohydrate intake (31). A recent, large, multicentre trial compared the effects of a diet containing $55 \%$ of energy as carbohydrate and $30 \%$ as fat with a diet of $40 \%$ carbohydrate and $45 \%$ fat (high monounsaturated fat) in 42 subjects with NIDDM who consumed each 
diet for six weeks (34). There was no significant difference between the diets on serum LDL or HDL cholesterol. The high carbohydrate diet produced a statistically significant, but small, increase in serum triglycerides from 1.75 to 2.19 $\mathrm{mmol} / \mathrm{L}(\mathrm{P}<0.0001)$. There was a significant increase in postprandial glucose and insulin with the high carbohydrate diet; however, a significant effect on the major component $1 \mathrm{C}$ of adult hemoglobin $\left(\mathrm{HbA}_{1 \mathrm{C}}\right)$ could not be demonstrated $(7.9 \%$ for the monounsaturated fat diet versus $8.2 \%$ for the high carbohydrate diet [not significant]). Thus, the issue of how much carbohydrate should be in the diabetic diet is still a matter of debate. If high carbohydrate intake is attempted, it may be important that the type of carbohydrate be unrefined, high in fibre and low in glycemic index. These types of carbohydrate are preferable because they may allow carbohydrate intake to be increased without increasing blood glucose, insulin and triglycerides (33).

The use of sugar by diabetic patients has traditionally been forbidden. However, consumption of sucrose (table sugar) produces a blood glucose response similar to or even lower than an equal amount of carbohydrate from most 'complex' carbohydrate foods such as bread (35). It has actually been shown recently that some sucrose-sweetened breakfast cereals produce a lower blood glucose response than an equivalent amount of the same unsweetened cereal (36). This is primarily because fructose produces a very low blood glucose response (35), and the molecule of sucrose contains glucose and fructose. In controlled studies in diabetes, isoenergetic replacement of starch with modest amounts of sucrose ( 28 to $45 \mathrm{~g} /$ day) has no effect on blood glucose or insulin in patients with diabetes (37-39). Even as much as 220 $\mathrm{g}$ sucrose/day in NIDDM patients has no effect on blood glucose control or blood lipids compared with a diet containing less than $3 \mathrm{~g}$ sucrose/day (40). There is some evidence that fructose as a sweetener actually improves glycemic control $(41,42)$. There is some concern that fructose may raise blood lipids in susceptible individuals (41) but this is not a universal finding (42). Thus, dietary recommendations are beginning to acknowledge that the use of modest amounts of sugar is acceptable. The problem is in defining what 'modest' means. The Canadian Diabetes Association suggests that the rather unrealistically low amount of 3 to $5 \mathrm{~g}$ of sucrose may be used by people with diabetes if glycosylated hemoglobin is normal or near normal. The concern of most dietitians regarding sugars is that it is easy to consume a large amount of carbohydrate and thus energy, which in turn influences blood glucose responses. Thus, while equal carbohydrate portions of whole fruits and fruit juices produce nearly the same blood glucose responses $(35,43)$, in practice, for example, a serving of apple juice $(250 \mathrm{~mL})$ has a greater effect on blood glucose than one whole apple because the juice contains nearly twice as much carbohydrate as a serving of a whole apple.

Dietary protein: Low protein intake has been proposed as a strategy to reduce the risk of diabetic nephropathy. Although not yet demonstrated in subjects with NIDDM, low protein intake has been shown to preserve renal function and slow the progression from early nephropathy to renal failure in persons with IDDM (44-46).

There is some evidence to suggest that reduced protein intake slows the development of diabetic retinopathy. However, other data suggest that the development of retinopathy may also be affected by hypertension, ageing, long term levels of glycemic control or some combination of all three $(11,21)$.

Another proposed rationale for reducing the protein intake of persons with NIDDM is to decrease the stimulating effects that ingested protein may have on insulin secretion and cholesterol synthesis (47). It remains unknown whether the theoretical advantage of protein restriction has practical value in devising food plans for individuals with NIDDM.

Dietary fat and cholesterol: Low fat diets have long been proposed as a method to reduce serum LDL cholesterol, and hence the risk of cardiovascular morbidity and mortality, in the general adult population. This may be a particularly important risk reduction strategy for persons with NIDDM. Cardiovascular disease (CVD) risk in diabetic patients is directly related to their levels of blood pressure, cigarette smoking and serum cholesterol. However, at any level of these risk factors, diabetic patients probably have three times the risk of CVD versus nondiabetics (48). Thus, levels of serum cholesterol that would be considered acceptable in a nondiabetic may impart considerable CVD risk in an individual with diabetes because in diabetics, lipoprotein particles are modified by glycation, aggregation and oxidation; glycated LDL particles are cleared very slowly from the body, contribute to the production of foam cells and are thought to stimulate atherogenic pathophysiology (49).

There is some uncertainty concerning the significance of fasting versus postprandial lipid abnormalities in NIDDM. However, some research in patients with NIDDM suggests that fasting hypertriglyceridemia may be a very important predictor of rapidly evolving atherogenic changes in postprandial lipids and lipoproteins. These postprandial lipid changes can potentiate the already unfavourable atherogenic fasting lipid profiles of many patients with NIDDM (50). Detection of fasting hypertriglyceridemia may be an important opportunity for intensification of diet and other therapeutic efforts (eg, smoking cessation) to mitigate excess risk of atherosclerosis among patients with NIDDM.

For many patients with NIDDM blood lipids can be managed through weight loss, adherence to a low fat, high fibre, high carbohydrate diet or through pharmacological achievement of glycemic control $(29,47)$. For others, an individualized evaluation of the etiology of the lipid abnormality and introduction of selected antilipemic medications may be necessary.

Increased meal frequency: Some researchers have explored increased meal frequency as a therapeutic strategy in NIDDM. The consumption of one large meal produces a glycemic challenge. In response, post-meal rises in insulin are followed by a rebound of counterregulatory hormones 180 mins later (eg, glucagon and growth hormone). However, when a person eats or sips the same nutrients slowly, blood in- 
TABLE 4

Examples of common foods and their glycemic index*

\begin{tabular}{|c|c|c|c|}
\hline Food & Glycemic index & Food & Glycemic index \\
\hline Breads & & Snack foods & \\
\hline Rye (whole grain & 68 & Corn chips & 99 \\
\hline pumpernickel) & & Potato chips & 77 \\
\hline Rye (crispbread) & 95 & Vegetables & \\
\hline Wheat (white or whole- & 100 & Potato (instant) & 120 \\
\hline meal) & & Potato (mashed) & 98 \\
\hline Pasta & & Potato (boiled) & 80 \\
\hline Macaroni & 64 & Potato (sweet) & 70 \\
\hline Spaghetti (wholewheat) & 61 & Baked beans (canned) & 70 \\
\hline Spaghetti (white) & 67 & Chick peas (canned) & 60 \\
\hline Cereal grains & & Green peas (frozen) & 65 \\
\hline Barley & 36 & Kidney beans (canned) & 74 \\
\hline Buckwheat & 78 & Lentils (red) & 38 \\
\hline Bulgur & 65 & Peanuts & 15 \\
\hline Millet & 103 & Fruits & \\
\hline Rice (polished or brown) & 81 & Apple & 52 \\
\hline Rice (parboiled) & 68 & & \\
\hline Corn & 80 & Raisins & $\begin{array}{l}84 \\
93\end{array}$ \\
\hline Breakfast cereals & & & 93 \\
\hline All Bran & 74 & Sugars & \\
\hline Corn Flakes & 121 & Fructose & 26 \\
\hline Muesli & 96 & Glucose & 138 \\
\hline Oat bran & 80 & Sucrose & 83 \\
\hline Puffed rice & 132 & Lactose & 57 \\
\hline Puffed wheat & 110 & Dairy products & \\
\hline Shredded wheat & 97 & Ice cream & 69 \\
\hline Cookies & & Skim milk & 46 \\
\hline Oatmeal & 78 & Whole milk & 44 \\
\hline Matzo & 100 & Yogurt & 52 \\
\hline Shortbread & 88 & & \\
\hline
\end{tabular}

${ }^{*}$ The glycemic index (GI) is a classification of the blood glucose raising potential of different foods defined as: $\mathrm{Gl}=100 \times \mathrm{F} / \mathrm{B}$, where $\mathrm{F}$ is the incremental area under the blood glucose response curve to a $50 \mathrm{~g}$ available carbohydrate portion of a food and $\mathrm{B}$ is the glycemic response to a $50 \mathrm{~g}$ carbohydrate portion of white bread taken by the same subject. Based on reference 35

sulin responses are flattened and there is continued suppression of counterregulatory hormones during the postprandial phase.

Healthy volunteers who consumed 17 small meals/day for two weeks had a $25 \%$ reduction in daytime insulin levels compared with a group who ate the identical diet as three meals/day (51). The former subjects experienced a 20\% decrease in cholesterol and marked reductions in LDL and apolipoprotein-B due to increased meal frequency (51). These lipemic effects of increased meal frequency may be especially beneficial for patients with NIDDM because of their increased risk of accelerated atherosclerosis $(49,52)$.

A recent study in patients with NIDDM confirmed that a daily diet of 13 small meals lowers blood glucose, serum insulin, C-peptide and triglycerides compared with an isocaloric, three meals daily diet of identical composition (53). These and other studies suggest that higher than normal meal frequency may be a useful way to limit glucose excursions and to reduce resulting insulin and free fatty acid levels in patients with NIDDM $(54,55)$.

The long term importance of increased meal frequency remains unknown because there are no long term trials in diabetic subjects to indicate the optimal number of meals/day. The Canadian Diabetes Association recommends at least three meals/day, with snacks added according to patient preference and the hypoglycemic agents used (56). The British Diabetes Association recommends small, frequent meals (47). The American Diabetes Association is flexible in the number of daily meals but recommends that calories be spread evenly throughout the day, which helps to avoid a large concentration at one meal and allows time for postprandial glucose levels to return to preprandial levels before eating again (57).

Compliance with small, frequent meals may be difficult given our modern lifestyle. Erratic eating patterns, fasting, binging and gross malnutrition are not uncommon among North American adults. When frequent meals are considered as a treatment modality the therapeutic benefit:risk ratio is high and the cost is low. Nonetheless, compliance with frequent meals may be as difficult for patients as compliance with multiple medication dosages. However, if compliance can be elicited through effective provider-patient communication, increased meal frequency may be useful in the treatment of NIDDM $(58,59)$. 


\section{NEWER THERAPEUTIC APPROACHES VIA THE GUT}

There are several nutritional and pharmacological means to mimic the actions of increased meal frequency and to slow the rate of carbohydrate absorption from the gut (53). Clinical studies using soluble fibre, low glycemic index foods or alpha glucosidase inhibitors have demonstrated that carbohydrate absorption can be slowed and redistributed throughout the intestine with significant therapeutic benefit. Slowing absorption lowers peak postprandial serum blood sugar levels and shortens the duration of hyperglycemia. These changes slow the secretion of insulin, and reduce postprandial rebound of free fatty acids and counterregulatory hormones. This results in more efficient carbohydrate metabolism and reduced secondary risks from hyperglycemia and hyperinsulinemia.

\section{DIETARY FIBRE}

Viscous forms of dietary fibre have been used to improve metabolic control in diabetes by slowing carbohydrate absorption. Guar gum, gum tragacanth and psyllium fibre reduce postprandial blood glucose and insulin levels in patients with NIDDM and may decrease cholesterol and triglyceride levels $(60,61)$. In general, purified viscous fibres have been shown to produce statistically significant long term reductions in blood glucose and cholesterol in 60 to $80 \%$ of studies, whereas the more palatable nonviscous fibres (eg, wheat bran) have shown positive results in only about $20 \%$ of studies (62). However, viscous fibre may not be effective in poorly controlled diabetic patients (63) nor provide any additional benefit compared with a low calorie diet in newly diagnosed or obese patients (64).

A major problem with the use of purified viscous fibres in diabetes management is its poor availability. Palatable, fibre-enriched foods are not widely available except in the form of a commercial psyllium-enriched cereal (65).

The way in which fibre is consumed has also been shown to be important. Fibre must be intimately mixed with food to have a salutary effect on blood glucose (65) and serum cholesterol (66). Attempts to ingest fibre packaged in gelatin capsules have generally not been shown to be effective.

The use of foods naturally high in fibre may be preferable to the use of purified fibre supplements. However, wheat and other cereal fibres, which are most familiar to the North American palate, have minimal short or long term effects on blood glucose. Diets rich in foods that are high in soluble fibre (eg, legumes and barley) have been shown to improve blood glucose control, but are less familiar and unpalatable to some. Thus, the practical benefits of high fibre diets have been seen as equivocal by diabetologists throughout North America.

\section{GLYCEMIC INDEX AND DIET}

Independent of fibre content, some foods are naturally absorbed at slower rates (Table 4). For example, breads containing a high proportion of whole cereal grains are more slowly absorbed and result in lower postprandial glucose levels versus breads made with milled flour $(35,67)$.

An intake of low glycemic index foods has been shown to reduce fasting blood glucose and $\mathrm{HbA}_{1} \mathrm{C}$, reflecting improved long term glycemic control (68). Low glycemic index foods may also have useful effects on blood lipids and renal function (68). The inclusion of low glycemic index foods into the diet may be an effective, inexpensive way to improve blood glucose control without increasing insulin demand (69). However, before the full use and clinical evaluation of the glycemic index can be implemented, further research is needed to categorize foods fully and to assess their effect in mixed meals (eg, carbohydrates taken with proteins and fats) (70).

\section{ALPHA GLUCOSIDASE INHIBITORS}

Also known as intestinal disaccharides inhibitors, alpha glucosidase inhibitors have been shown to blunt postprandial hyperglycemia by delaying the absorption of carbohydrates. Acarbose, a new and promising alpha glucosidase inhibitor, is an oligosaccharide extracted from culture broth of the fungus actinomycetes. Acarbose is taken as a chewable tablet or sprinkled onto food and is minimally absorbed. It competitively inhibits carbohydrate absorption in the proximal small intestine by preferentially binding to brush border enzymes (ie, glucoamylase, sucrase maltase, isomaltase). This drug's net effect is to delay carbohydrate absorption until nutrients reach the ileum $(71,72)$. Thus, acarbose prolongs absorptive time and flattens the blood sugar, insulin and gastric inhibitory peptide responses. The effect of acarbose on blood lipids is variable and there is no evidence that insulin sensitivity in the peripheral tissues of NIDDM patients is improved by the use of alpha glucosidase inhibitors (71).

Used alone or in combination with oral agents, acarbose has been shown to improve blood glucose control in patients with NIDDM $(71,72)$. Other studies have shown monotherapy with acarbose to be equal in efficacy to sulphonylureas, as demonstrated by improvements in fasting and postprandial blood sugar levels and glycohemoglobin.

Several other alpha glucosidase inhibitors are also under development (eg, AO-128, emiglitate and miglitol). In addition to glycemic control benefits, some of these may promote weight loss in obese patients with NIDDM (73).

\section{PRACTICAL ISSUES IN NUTRITIONAL APPROACHES TO DIABETES MELLITUS MANAGEMENT}

Compliance: Patient compliance with dietary regimens is notoriously difficult. However, research has shown that intensive patient education, behaviour modification counselling or both can elicit significant improvements in glycemic control, weight loss and quality of food choices in NIDDM patients $(74,75)$. Meal planning is often based on the Canadian Diabetes Association recommendations, but can also be individualized to accommodate cultural and personal preferences. Compliance is improved when the patient and family 
participate in setting weight loss goals and meal planning. Efforts to improve physician-patient communication may also be essential to the success of low calorie, weight loss diets and other dietary interventions for $\operatorname{NIDDM}(58,59)$.

Home blood glucose monitoring and patient response: Home blood glucose monitoring to guide dietary intake and/or physical exertion may be underused by patients with NIDDM (76,77). A recent survey of diabetes management practices suggests that most diabetics are not instructed to use home blood glucose monitoring data in this manner (76). Consequently, many patients who self-monitor blood glucose may modify their insulin or oral hypoglycemic agent dosages, but not alter their food intake or exercise patterns in response to blood sugar abnormalities (77). Further research is needed to identify and educate NIDDM patients who would benefit from self-adjustment of dietary intake (and/or exercise patterns) on the basis of home blood glucose monitoring (76).

Counselling to promote weight loss or maintain ideal body weight is also important to NIDDM management. However, not all physicians have the time or skills to counsel patients effectively. One study reported a 50\% discrepancy between patient and physician understanding of overall treatment goals, weight loss goals and blood glucose goals (78).

Diabetes educators may be helpful to promote weight loss and early symptom recognition, to teach home blood glucose monitoring and to enhance family support for NIDDM pa-

\section{REFERENCES}

1. Reaven GM. Banting Lecture 1988: Role of insulin resistance in human disease. Diabetes 1988;37:1595-607.

2. Campbell P, Carlson MG. Impact of obesity on insulin action in NIDDM. Diabetes 1993;42:405-10.

3. Lillioja S, Nyomba BL, Saad MF, et al. Exaggerated early insulin release and insulin resistance in a diabetes-prone population: a metabolic comparison of Pima Indians and Caucasians. J Clin Endocrinol Metab 1991;73:866-76.

4. Fürnsinn C, Komjati M, Madsen OD, Schneider B, Waldhausl W. Lifelong sequential changes in glucose tolerance and insulin secretion in genetically obese Zucker rats (fa/fa) fed a diabetogenic diet. Endocrinology 1991;128:1093-9.

5. Groop LC, Saloranta C, Shank M, Bonadonna RC, Ferrannini E, DeFronzo RA. The role of free fatty acid metabolism in the pathogenesis of insulin resistance in obesity and non-insulin dependent diabetes mellitus.

J Clin Endocrinol Metab 1991;72:96-107.

6. DCCT Research Group. The effect of intensive treatment of diabetes on the development and progression of long-term complications in insulin-dependent diabetes mellitus. N Engl J Med 1993;329:977-86.

7. Reichard P, Nilsson B-Y, Rosenqvist U. The effect of long-term intensified insulin treatment on the development of microvascular complications of diabetes mellitus. N Engl J Med 1993;329:304-9.

8. American Diabetes Association. Position statement: Implications of the Diabetes Control and Complications Trial. Diabetes Care 1993;16:1517-20.

9. Lasker RD. The Diabetes Control and Complications Trial: Implications for policy and practice. N Engl J Med 1993;329:1035-6.

10. Raskin P, Rosenstock J. Blood glucose control and diabetic complications. Ann Intern Med 1986;105:254-63.

11. Naliboff BD, Rosenthal M. Effects of age on complications in adult onset diabetes. J Am Geriatr Soc 1989;37:838-42.

12. UK Prospective Diabetes Study Group. UK Prospective Diabetes Study (UKPDS). VIII. Study design, progress and performance. Diabetologia 1991;34:877-90.

13. Abraira C, Emanuele N, Colwell J, et al, for the VA CS Group. Glycemic control and complications in type II diabetes. Diabetes Care 1992;15:1560-71.

14. Van Der Does FE, Bouter LM, Heine RJ. Glycemic control and complications in type II diabetes. Diabetes Care 1993;16:952.

15. Stout RW. Insulin as a mitogenic factor: Role in the pathogenesis of cardiovascular disease. Am J Med 1991;90(Suppl 2A):62S-5S. tients (79). Patient counselling by physicians alone may not be effective or sufficient, and early referral to dieticians or other health care educators is important within the context of contemporary diabetes management $(80,81)$.

\section{CONCLUSIONS}

In addition to the standard treatment options, there are several innovative dietary and pharmacological ways to approach the management of NIDDM.

Research has shown that hyperinsulinemia, hyperglycemia and other metabolic abnormalities can be significantly affected by manipulating gastrointestinal function. It may be possible for patients with NIDDM to improve glycemic control and reduce atherosclerotic risk factors through an intake of low glycemic index foods, a high fibre diet, increased meal frequency or the use of alpha glucosidase inhibitors.

As a broader array of treatment approaches becomes available for patients with NIDDM, physicians and other members of the diabetes health care team will need to work closely with patients and their families to realize the benefits of advances in NIDDM management (82).

ACKNOWLEDGEMENTS: The author's work in the area has been supported by the Canadian Diabetes Association, the $\mathrm{Na}$ tional Institutes of Health, the Natural Sciences and Engineering Research Council of Canada, Kellogg Canada, Ontario Ministry of Health and Bayer Inc.

16. Rodwell VW, Nordstrom JL, Mitschelen JJ. Regulation of HMG-CoA reductase. Adv Lipid Res 1976;14:1-76.

17. Ducimetiere P, Eschwege E, Papoz L, Richard JL, Claude JR, Rosselin G. Relationship of plasma insulin levels to the incidence of myocardial infarction and coronary heart disease mortality in a middle aged population. Diabetologia 1980;19:205-10.

18. Daly P, Landsberg L. Hypertension in obesity and NIDDM: Role of insulin and the sympathetic nervous system. Diabetes Care 1991;14:240-8.

19. Pascoe WS, Storlien LH. Inducement by fat feeding of basal hyperglycemia in rats with abnormal $\beta$-cell function: Model for study of etiology and pathogenesis of NIDDM. Diabetes 1990;39:226-33.

20. Swinburn BA, Boyce VL, Bergman RN, Howard BV, Bogardus C. Deterioration in carbohydrate metabolism and lipoprotein changes induced by modern, high fat diet in Pima Indians and Caucasians. J Clin Endocrinol Metab 1991;73:156-65.

21. Roy MS, Stables G, Collier B, Roy A, Bou E. Nutritional factors in diabetics with and without retinopathy. Am J Clin Nutr 1989;50:728-30.

22. Gordon B, Chang S, Kavanagh M, et al. The effects of lipid lowering on diabetic retinopathy. Am J Ophthalmol 1991;112:385-91.

23. Leske MC, Chylakc LT, Wu SY. The lens opacities case-control study: risk factors for cataract. Arch Ophthalmol 1991;109:244-51.

24. Wing RR, Marcus MD, Salata R, Epstein LH, Miaskiewicz S, Blair $\mathrm{EH}$. Effects of a very-low-calorie diet on long-term glycemic control in obese type 2 diabetic subjects. Arch Intern Med 1991;151:1334-40.

25. Watts NB, Spanheimer RG, DiGirolamo M, et al. Prediction of glucose response to weight loss in patients with non-insulindependent diabetes mellitus. Arch Intern Med 1990;150:803-6.

26. Lomasky SJ, D'Eramo G, Shamoon H, Fleischer N. Relationship of insulin secretion and glycemic response to dietary intervention in non-insulin- dependent diabetes. Arch Intern Med 1990;150:169-72.

27. Wing RR, Blair EH, Bononi P, Marcus MD, Watanabe R, Bergman RN. Caloric restriction per se is a significant factor in improvements in glycemic control and insulin sensitivity during weight loss in obese NIDDM patients. Diabetes Care 1994;17:30-6.

28. Henry RR, Scheaffer L, Olefsky JM. Glycemic effects of intensive caloric restriction and isocaloric refeeding in noninsulin-dependent diabetes mellitus. J Clin Endocrinol Metab 1985;61:917-25.

29. Canadian Diabetes Association. Guidelines for the nutritional management of diabetes mellitus in the 1990s. Beta Release 1989;13:8-17. 
30. Reaven GM. Dietary therapy for non-insulin-dependent diabetes mellitus. N Engl J Med 1988;319:862-4.

31. Bonanome A, Visona A, Lusiani L, et al. Carbohydrate and lipid metabolism in patients with non-insulin-dependent diabetes mellitus: effects of a low-fat, high carbohydrate diet vs a diet high in mono-unsaturated fatty acids. Am J Clin Nutr 1991;54:586-90.

32. Stacpoole PW. Should NIDDM patients be on high-carbohydrate, low fat diets? Hosp Pract 1992;27(Suppl 1):6-10.

33. Garg A, Grundy SM, Unger RH. Comparison of effects of high and low carbohydrate diets on plasma lipoproteins and insulin sensitivity in patients with mild NIDDM. Diabetes 1992;41:1278-85.

34. Garg A, Bantle JP, Henry RR, et al. Effects of varying carbohydrate content of diet in patients with non-insulin-dependent diabetes mellitus. J Am Med Assoc 1994;271:1421-8.

35. Wolever TMS. Glycaemic index revisited. In: Marshall SM, Home PD, Alberti KGMM, Krall LP, eds. The Diabetes Annual/7. Amsterdam: Elsevier Science Publishers BV, 1993:258-72.

36. Brand Miller JC, Lobbezoo I. Replacing starch with sucrose in a high glycaemic index breakfast cereal lowers glycaemic and insulin responses. Eur J Clin Nutr 1994;48:749-52.

37. Cooper PI, Wahlqvist ML, Simpson RW. Sucrose versus saccharine as an added sweetener in non-insulin- dependent diabetes: short- and medium-term metabolic effects. Diabetic Med 1988;5:676-80.

38. Peterson DB, Lambert J, Darling P, Carter RD, Jelfs R, Mann JI. Sucrose in the diet of diabetic patients - just another carbohydrate? Diabetologia 1986;29:216-20.

39. Chanteleau EA, Gösseringer G, Sonnenberg GE, Berger M. Moderate intake of sucrose does not impair metabolic control in pump-treated diabetic out-patients. Diabetologia 1985;28:204-7.

40. Jellish WS, Emanuele MA, Abraira C. Graded sucrose/carbohydrate diets in overtly hypertriglyceridemic diabetic patients. Am J Med 1984;77:1015-22.

41. Crapo PA, Kolterman OG, Henry RR. Metabolic consequences of two-week fructose feeding in diabetic subjects. Diabetes Care 1986;9:111-9.

42. Osei K, Bossetti B. Dietary fructose as a natural sweetener in poorly controlled type 2 diabetes: a 12-month crossover study of effects on glucose, lipoprotein and apolipoprotein metabolism. Diabetic Med 1989;6:506-11

43. Wolever TMS, Vuksan V, Katzman-Relle L, et al. Glycaemic index of some fruits and fruit products in patients with diabetes. Int J Food Sci Nutr 1993;43:205-12.

44. Zeller K, Whittaker E, Sullivan L, Raskin P, Jacobson HR. Effect of restricting dietary protein on the progression of renal failure in patients with insulin-dependent diabetes mellitus. N Engl J Med 1991;324:78-84.

45. Brodsky IG, Robbins DC, Hiser E, Fuller SP, Fillyaw M, Devlin JT. Effects of low-protein diets on protein metabolism in insulin-dependent diabetes mellitus patients with early nephropathy. J Clin Endocrinol Metab 1992;75:351-7.

46. Brouhard BH, LaGrone L. Effect of dietary protein restriction on functional renal reserve in diabetic nephropathy. Am J Med 1990;89:427-31.

47. Hagan J, Wylie-Rosett J. Lipids: impact on dietary prescription in diabetes. J Am Diet Assoc 1989;89:1104-8.

48. Stamler J, Vaccaro O, Neaton JD, Wentworth D. Diabetes, other risk factors, and 12 year cardiovascular mortality of men screened in the multiple risk factor intervention trial. Diabetes Care 1993;16:434-44

49. American Diabetes Association. Detection and management of lipid disorders in diabetes. Diabetes Care 1993;16:828-34.

50. Lewis GF, O'Meara NM, Soltys PA, et al. Fasting hypertriglyceridemia in noninsulin-dependent diabetes mellitus is an important predictor of postprandial lipid and lipoprotein abnormalities. J Clin Endocrinol Metab 1991;72:934-44.

51. Jenkins DJ. Nibbling versus gorging: metabolic advantages of increased meal frequency. N Engl J Med 1989;321:929-34.

52. Fábry P, Tepperman, J. Meal frequency - a possible factor in human pathology. Am J Clin Nutr 1970;23:1059-68.

53. Jenkins DJA, Ocana A, Jenkins AL, et al. Metabolic advantages of spreading the nutrient load: effects of increased meal frequency in non-insulin-dependent diabetes. Am J Clin Nutr 1992;55:461-7.

54. Bertelsen J, Christiansen C, Thomsen C, et al. Effect of meal frequency on blood glucose, insulin, and free fatty acids in NIDDM subjects. Diabetes Care 1993;16:4-7.

55. Beebe CA, Pastors JG, Powers MA, Wylie-Rosett J. Nutritional management for individuals with non-insulin dependent diabetes mellitus in the 1990s: A review by the Diabetes Care and Education Dietetic Practice Group. J Am Diet Assoc 1991;91:196-202,205-7.

56. British Diabetes Association. Nutrition Sub-committee of the British Diabetes Association's Medical Advisory Committee. Dietary recommendations for diabetics for the 1980 s - A policy statement by the British Diabetic Association. Hum Nutr Appl Nutr 1982;36A:378-94.
57. American Diabetes Association. Physicians Guide to Non-Insulin Dependent (Type II) Diabetes: Diagnosis and Treatment, 2nd edn. Alexandria: American Diabetes Association, 1989:26-7.

58. Greenfield S, Kaplan SH, Ware JE, Yano EM, Frank HJL. Patients' participation in medical care: Effects on blood sugar control and quality of life in diabetes. J Gen Intern Med 1988;3:448-57.

59. Street RL, Piziak VK, Carpentier WS, et al. Provider-patient communication and metabolic control. Diabetes Care 1993;16:714-21.

60. Hagander B, Asp N-G, Efendic S, Nilssen-Ehle P, Scherstén B. Dietary fiber decreases fasting blood glucose levels and plasma LDL concentrations in noninsulin-dependent diabetes mellitus patients. Am J Clin Nutr 1988;47:852-8.

61. Pastors JG, Blaisdell PW, Balm TK, Asplin CM, Pohl SL. Psyllium fibre reduces rise in postprandial glucose and insulin concentrations in patients with non-insulin-dependent diabetes. Am J Clin Nutr 1991;53:1431-5

62. Wolever TMS, Jenkins AJA. Effect of dietary fiber and foods on carbohydrate metabolism. In: Spiller GA, ed. CRC Handbook of Dietary Fiber in Human Nutrition, 2nd edn. Boca Raton: CAC Press, Inc, 1993:111-52.

63. Uusitupa M, Siitonen O, Savolainen K, Silvasti M, Penttila I, Parviainen M. Metabolic and nutritional effects of long-term use of guar gum in the treatment of noninsulin-dependent diabetes of poor metabolic control. Am J Clin Nutr 1989;49:345-51.

64. Beattie VA, Edwards CA, Hosker JP, Cullen DR, Ward JD, Read NW. Does adding fibre to a low energy, high carbohydrate low fat diet confer any benefit to the management of newly diagnosed overweight type II diabetics? BMJ Clin Res Ed 1988;296:1147-9.

65. Wolever TMS, Vuksan V, Eshuis H, et al. Effect of method of administration of psyllium on glycemic response and carbohydrate digestibility. J Am Col Nutr 1991;10:364-71.

66. Wolever TMS, Jenkins DJA, Mueller S, et al. Method of administration influences the serum cholesterol-lowering effect of psyllium. Am J Clin Nutr 1994;59:1055-9.

67. Jenkins DJA, Wesson V, Wolever TMS, et al. Wholemeal versus wholegrain breads: Proportion of whole or cracked grain and the glycemic response. BMJ 1988;297:958-60.

68. Wolever TM, Jenkins DJ, Jenkins AL, Josse RG. The glycemic index: Methodology and clinical implications. Am J Clin Nutr 1991;54:846-54

69. Wolever TMS, Jenkins DJA, Vuksan V, et al. Beneficial effect of a low-glycaemic index diet in type 2 diabetes. Diabet Med 1992;9:451-8

70. American Diabetes Association. Nutritional recommendations and principles for individuals with diabetes mellitus. Diabetes Care 1993;16(Suppl 2):22-9.

71. Jenny A, Proietto J, O'Dea K, Nankervis A, Traianedes K, D'Embden $\mathrm{H}$. Low dose acarbose improves glycemic control in NIDDM patients without changes in insulin sensitivity. Diabetes Care 1993;16:499-502.

72. Chiasson J-L, Josse RG, Hunt JA, et al. The efficacy of acarbose in the treatment of patients with non-insulin-dependent diabetes mellitus. A multicenter controlled clinical trial. Ann Intern Med 1994;121:928-35.

73. Matsuo T, Odaka H, Ikeda H. Effect of an intestinal disaccharidase inhibitor (AO0128) on obesity and diabetes. Am J Clin Nutr 1992;55(Suppl 1): 314S-7S

74. Laitinen JH, Ahola IE, Sarkkinen ES, Winberg RL, Harmaakorpi-Iivonen PA, Uusitupa MI. Impact of intensified diet therapy on energy and nutrient intakes and fatty acid composition of serum lipids in patients with recently diagnosed NIDDM. J Am Diet Assoc 1993;93:276-83.

75. Welch G, Smith RB. The evaluation of a behavioral food and weight control programme for obese patients with NIDDM. NZ Med J 1992;105:9-10.

76. Welch G, Smith RBW. Adjustment of caloric intake based on self-monitoring in noninsulin-dependent diabetes mellitus: development and feasibility. J Am Diet Assoc 1989;89:960-1

77. Tuttleman M, Lipsett L, Harris MK. Attitudes and behaviors of primary care physicians regarding tight control of blood glucose in IDDM patients. Diabetes Care 1993;16:765-72.

78. D'Eramo-Melkus GA, Demas P. Patient perceptions of diabetes treatment goals. Diabetes Educ 1989;15:440-3.

79. Schorfheide AM, Eaks GA, Hamera EK, Cassmeyer VL. Enhancing self-care in diabetes management using self-regulatory processes. J Community Health Nurs 1989;6:165-71.

80. Arnold MS, Stepien CJ, Hess GE, Hiss RG. Guidelines vs practice in the delivery of diabetes nutrition care. J Am Diet Assoc 1993;93:34-9.

81. Franz MJ. Practice guidelines for nutrition care by dietetics practitioners for outpatients with non-insulin-dependent diabetes mellitus: Consensus statement. J Am Diet Assoc 1992;92:1136-9.

82. Norris RM. Critique of current therapies of noninsulin-dependent diabetes mellitus. Prog Clin Biol Res 1988;265:151-9. 


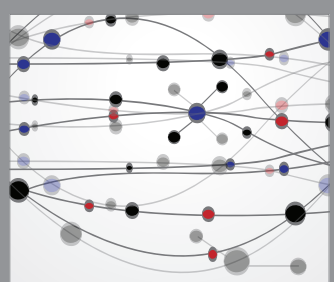

The Scientific World Journal
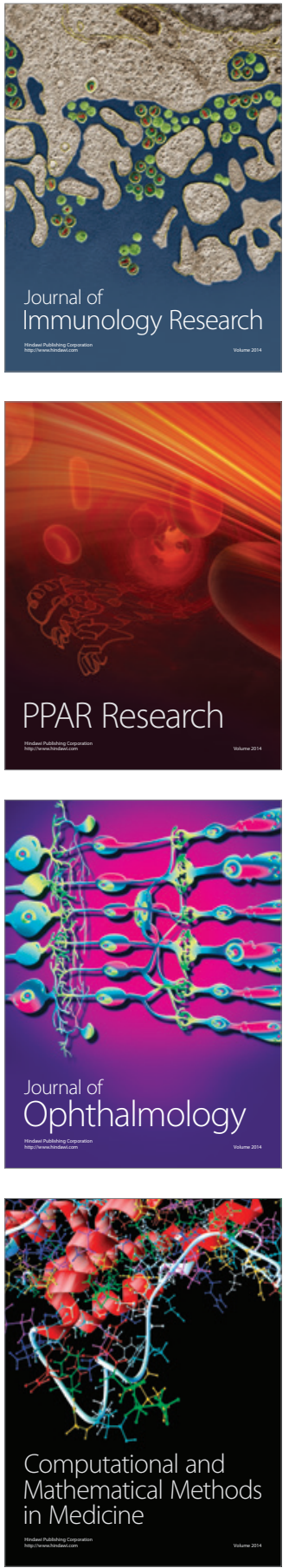

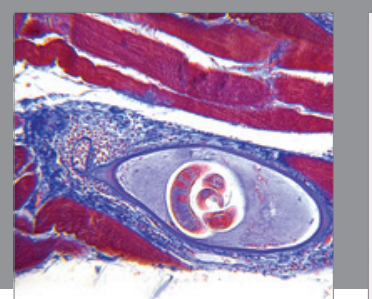

Gastroenterology Research and Practice

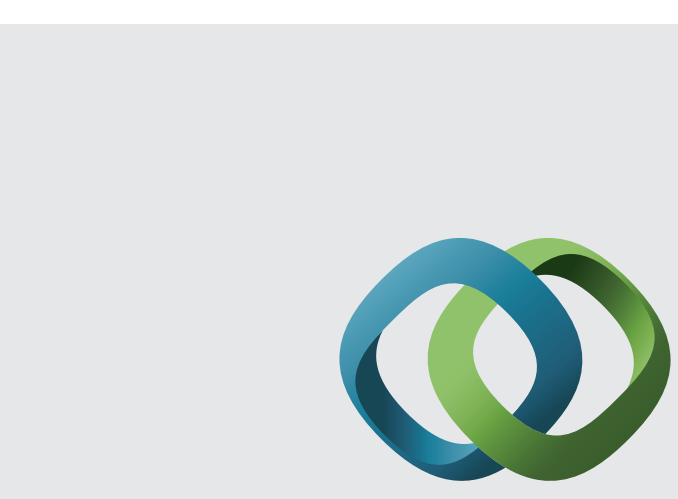

\section{Hindawi}

Submit your manuscripts at

http://www.hindawi.com
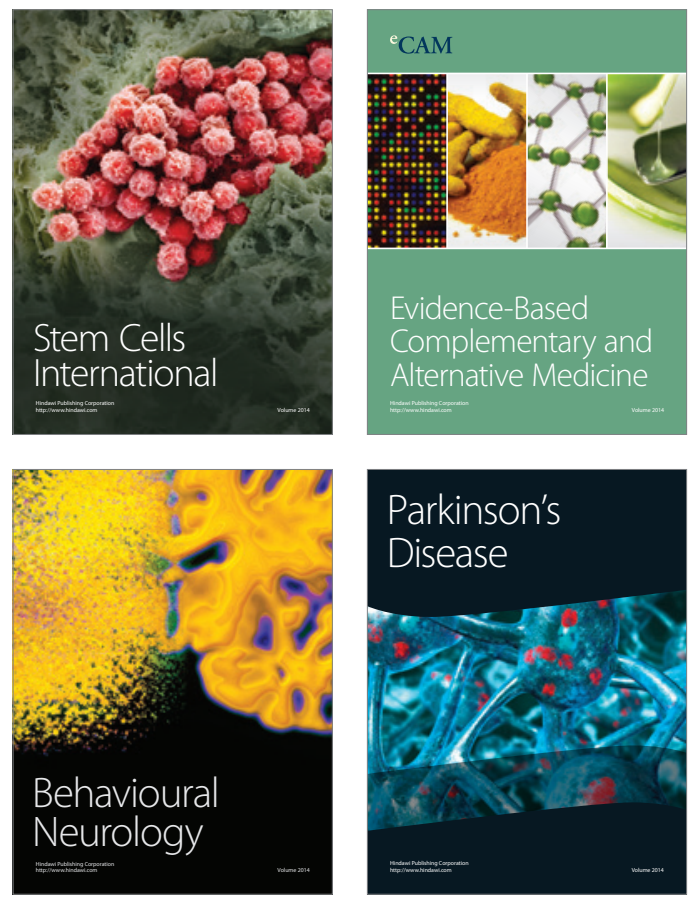
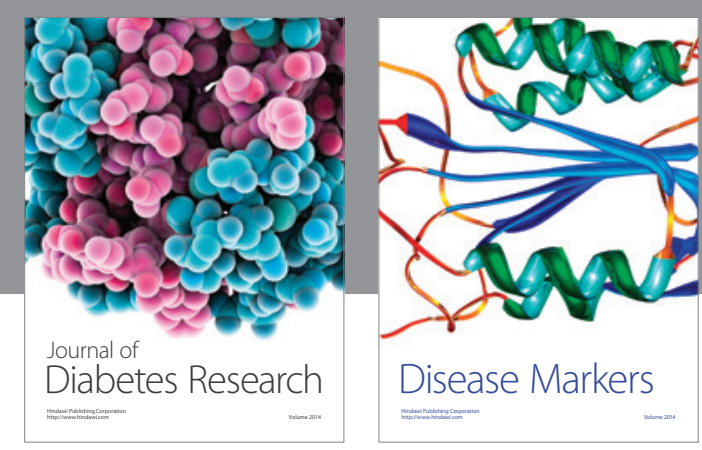

Disease Markers
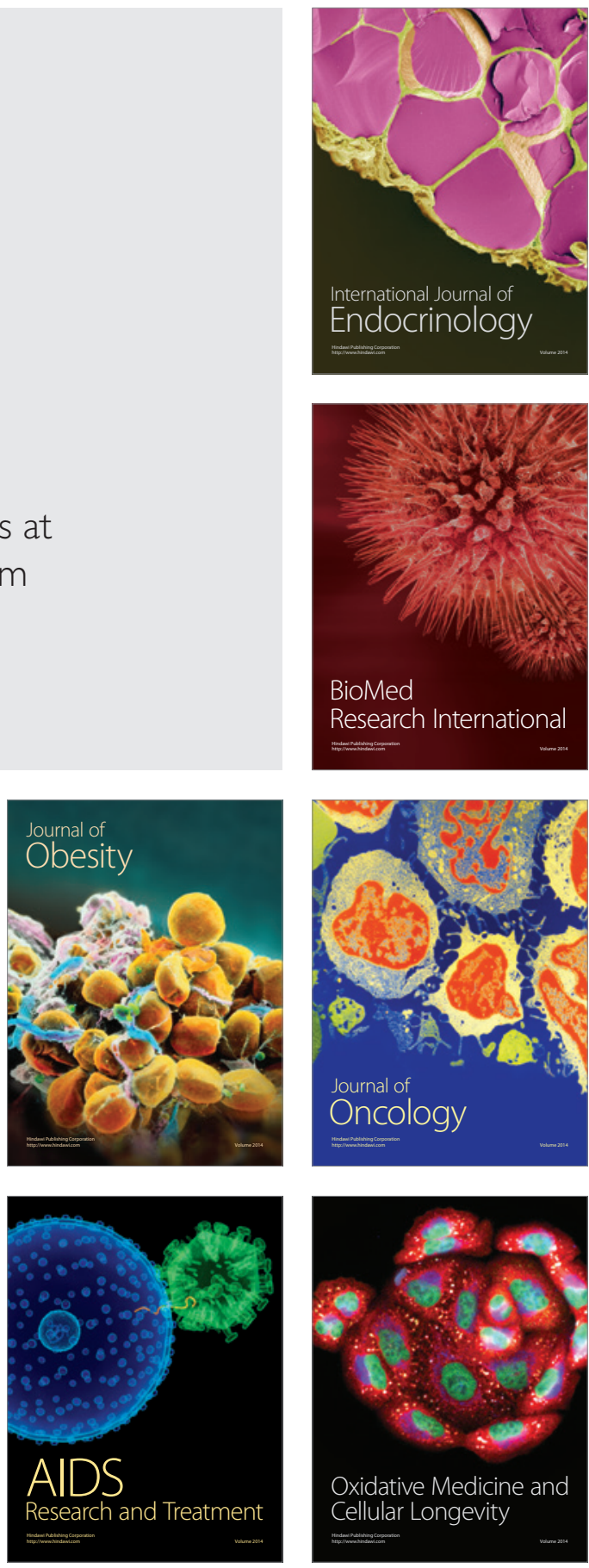